\title{
Systemic health reform should be a higher priority in African aid projects, experts say
}

$\mathrm{S}$ hort-term cash injections, shortsighted pilot projects and a revolving door of international health priorities have done little to bolster much needed public health infrastructure in Africa, health development experts argue.

Despite an increase in health spending in Africa, many people still have limited access to good quality care as most funding has been targeted toward the treatment of specific diseases, rather than toward improving health systems and services as a whole, Dr. Teguest Guerma, director general of the African Medical and Research Foundation (AMREF), said during a public forum on maternal and child health hosted by the North-South Institute and the Canadian International Development Agency.

International donors should shift their dollars from one-off disease-based projects to support public health education and disease prevention, more training for nonphysician health workers, and improvements in basic health care infrastructure across the continent, Guerma added at the forum on Effective Strategies for Improving the Health of Mothers and Children across Africa held in Gatineau, Québec, in April.

"Every donor comes in saying, 'I want a cost effective program, I want to save lives, so I want you to do this, this and this, and get these results.' Nobody wants to fund institutional support, because to go to the root of the problem takes time. You cannot save lives in a minute or a day and also have a wellorganized, sustainable health system," she explained. "If it continues this way, it cannot be effective in the long term."

Part of the problem is that health ministries in most countries are "very weak" and don't have the organization to set a long-term agenda for the use of funds, she added. For that reason, "coordination should come from the donors ... because if every donor coming to us

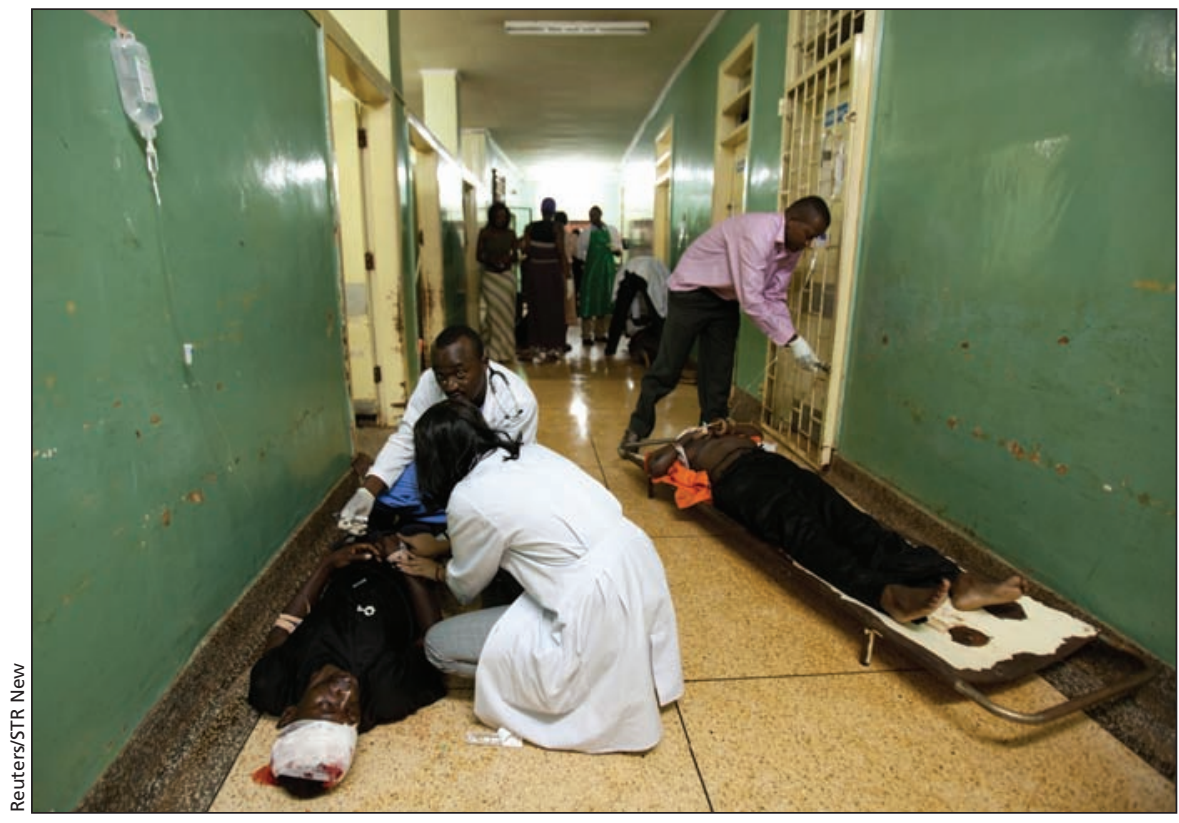

The basic health infrastructure in many African nations is desperately in need of improvement, health officials say. Here, staff attend to injured patients in the hallway of the Mulago Hospital in the Ugandan capital of Kampala.

says, 'This is what we'll give you, take it or leave it,' government will accept anything and put it in their pocket."

If donors don't tie accountability requirements to funding to ensure that programs work, substantive change will not occur, Guerma said. "Once pilot money is finished, most of the organizations close up and go. If a donor has funded a pilot that's proven by evidence to work, the organization and donor should advocate for the government to scale it up."

The problem has been exacerbated by constant turnover in global priorities for health development, she explained. "A couple years ago it was HIV/AIDS, then we forgot about that and the focus went to maternal and child health. And now I'm already hearing we're going to talk about noncommunicable diseases ... All the money's coming from the same boat but the priority changes too frequently."

Integrating disease-specific programs into local health systems and keeping them going after donor dollars run out, is a "perennial problem," agreed Joseph Ingram, president and CEO of the North-South Institute. For this reason, "it's the institutional projects that work."

It doesn't make sense to solely pump money into disease-specific treatments, Guerma concurred. Any treatment must be accompanied by education programs to prevent spread of the disease, measures to ensure that patients follow up on treatment plans and adequate health staff to administer treatments, particularly in remote communities.

Instead, greater emphasis is all too often placed on curative health care in hospitals and health centres in major towns and cities, Guerma said. "In practice, we have doctors who are only prescribing drugs, not going to communities to provide prevention. They're overworked and there's maybe only one of them to do everything, so understandably they focus their priorities on the curative part."

Some five million people with HIV in developing countries are being kept alive 
with antiretroviral therapies, according to AMREF. But one survey estimated that AIDS treatment programs consumed $20 \%-50 \%$ of the effort of health workers in two countries, and $10 \%$ in another 10 nations.

Africa is home to about $11 \%$ of the world's population, but has a mere $3 \%$ of the world's health workers tackling $24 \%$ of the global disease burden, largely as a consequence of preventable diseases such as HIV/AIDS, malaria and tuberculosis. The continent also accounts for $20 \%$ of the world's births but contributes to $40 \%$ of maternal deaths globally, many of which would also be preventable if proper and accessible health care were in place.
Africa needs one million more health workers in order to meet the United Nations' Millennium Development Goals for health, Guerma estimated. "But if we just train doctors, we'll never have enough."

Part of the problem is a lack of personnel to promote, provide and plan for more holistic care, she said, while arguing for more training and task shifting to nonphysician health workers. Clinical officers, she added, can perform $70 \%$ of doctors' tasks, can be trained faster and at a fifth of the cost.

But some physicians have protested such task shifting on the grounds that "laymen shouldn't write prescriptions or give injections," she explained.
Regardless of who provides the care, increased infrastructure is needed to support its timely and appropriate delivery to patients, Guerma added. "Sometimes we only have a building but we need drugs, supplies, equipment and ambulances to transport patients if they need a different level of care."

Guerma suggested public-private partnerships could be helpful in that regard. "Why are we struggling in the public sector to distribute antimalaria drugs when we have private companies like Coca Cola that already have distribution mechanisms well established?" — Lauren Vogel, CMAJ

CMAJ 2011. DOI:10.1503/cmaj.109-3866 